\title{
"When my mother called to say that the time of cutting had arrived, I escaped to Belgium with my daughter": Identifying turning points in the change of attitudes towards the practice of Female Genital Mutilation among migrant women in Belgium
}

\section{Afi A. Agboli ( $\square$ afi.agboli@uclouvain.be)}

Universite Catholique de Louvain Secteur des sciences de la sante https://orcid.org/0000-0003-37301563

\section{Fabienne Richard}

Universite Libre de Bruxelles Ecole de Sante Publique

Isabelle Aujoulat

Universite Catholique de Louvain Secteur des sciences de la sante

Research article

Keywords: Female genital mutilation, turning points, migrant women, patriarchal system, emotions.

Posted Date: January 15th, 2020

DOl: https://doi.org/10.21203/rs.2.20619/v1

License: (c) (i) This work is licensed under a Creative Commons Attribution 4.0 International License. Read Full License 


\section{Abstract}

\section{Background}

Female Genital Mutilation (FGM) remains a public health concern with negative consequences on women's health. It is a harmful practice and recognized in international discourses on public health as a form of gender-based violence of which women are not only victims, but also perpetrators. Although the practice of FGM remains a social norm which is difficult to change because of its deep roots in tradition and how it is embedded in the patriarchal system, some women have changed their attitudes towards it and speak out against it. This study identifies and describes turning points (TP) defined as significant events in the lives of the women, that create changes towards the practice of FGM.

Methods

We conducted an inductive qualitative study based on the life story approach where we interviewed 15 women with FGM. During the interviews the turning points that gave them the courage to change were identified together with the research participants. The analysis drew on lifeline reconstructions and thematic analysis.

Results

Six common turning points relating to a change in attitude towards FGM were identified: TPs related to encounters with health professionals, education, social interactions with other cultures and their own culture, experiences of motherhood, repeated pain during sexual or reproductive activity and to the fact witnessing some harmful consequences of FGM towards loved ones.

\section{Conclusion}

The turning points identified challenged the understanding of what it means to be a 'member' of the community in a patriarchal system, a 'normal woman' according to the community and what it means to be a good mother. In addition, the TPs found were expressed together with some issues related to emotional responses and coming to terms with conflict of loyalty, which we see as possible mechanisms to explain the change experienced by the women in our sample.

\section{Background}

Female Genital Mutilation is defined as all procedures whereby the external female genitals are removed for non-therapeutic reasons [1]. The practice is performed mainly in sub Sharan Africa as well as in Middle East, Indonesia and Malaysia [2]. It is estimated that two hundred million women and girls have been subjected to the practice worldwide [2]. International migration brought the practice to other parts of the world and it has become a global public health concern to host countries [3]. FGM is a harmful practice due to: (i) its consequences on women's health; (ii) its violation of women's bodily integrity, as a healthy organ is cut without medical reason but with the intention of reducing the woman's role to a child 
bearing one without functioning for sexual pleasure [4]. From both immediate to long term concerns, several studies have looked at the negative consequences of FGM in the lives and on the health of women who have undergone it $[1,5,6]$. Because of the harmful consequences on women's health, the practice of FGM is considered a gender-based violence, a violation of women's health rights and of human rights $[1,7]$. Because FGM is mainly performed on young children, it violates rights of children and undermines those of girls to health, security and physical integrity $[1,8]$.

The practice of FGM involves a whole community, making it a social norm everyone is expected to comply with [1]. In some FGM-practicing communities, FGM is a celebratory rite of passage which reinforces cultural and ethnic identity and a sense of belonging in the community [1,9]. Individuals and families believe their communities expect them to do it in order to ensure an honorable and worthy womanhood for their daughters [1]. Cultural cues reinforce the social significance of it and the practice is maintained for the strong meanings attached to it: virginity, beauty and purity, rite of passage to womanhood, and marriageability $[1,10]$. The practice as a norm is also reinforced through several other norms that are embedded in the patriarchal system. These norms include the submissiveness of girls throughout their childhood, roles of childbearing and rearing as well as the sexual satisfaction of men [4]. Grandmothers and mothers have the responsibility to be the guardians of the tradition and to perpetuate the practice to their daughters. Girls are taught to be brave and endure pain, therefore, not to express their emotions. The practice is often perpetrated upon women and girls by other women [10,11]. The related norms embedded in the patriarchal system together with the associated meanings of performing FGM make the practice resistant to change.

The paper seeks to explore what makes migrant women in Belgium who were once socialized in the FGM cultural context where female genital mutilation (FGM) is valued and normal change their attitudes towards the practice and speak out against it.

\section{Methods}

Qualitative methodology informed by the 'life story' narrative approach was used to investigate, identify and describe critical life events experienced by the women in their change of attitude towards the practice of FGM. Life stories research uses the concept of turning points (TP) to describe changes in the life trajectory of individuals [12]. Wheaton and Gotlib [13] claim that turning points can only be found in the context of life trajectories, and they define them as specific events perceived to change the direction of one's life [14]. These can only be identified in hindsight after the event has passed, and thus are subjective and retrospective reconstructions of life story narratives [15]. In the life course perspective, the events are revealed as something that helps people to change status from disadvantaged to successful, from criminal to non-criminal, from abused and battered to breaking out of the relationship and becoming free [16]. Embedded in one's life story, turning points are "shifts that force individuals to recognize that they are no longer who they used to be" [17]. 
This study focuses on TPs as significant events which create an awareness that challenges the existing internalized norms in relation to the practice of FGM.

\section{Sample (participants)}

Fifteen women who had experienced FGM were included in the sample. They were considered eligible to participate if they had undergone FGM, were 18 years or over, had been living in Belgium for at least one year, were from an FGM-practicing community from East or West Africa, spoke either French or English and self-reported as being against the practice of FGM. Ten women were recruited through gatekeepers from a non-profit organization, GAMS Belgique (Groupe pour l'Abolition des Mutilations Sexuelles féminines), which strongly opposes FGM. This initial convenience sample was followed by a snowball procedure that led to the inclusion of a further five women. The recruitment process took place between December 2016 and April 2017.

\section{Iterative process of data collection and data analysis}

In-depth interviews were conducted by the first author and each woman was interviewed twice according to the biographical narrative interview method (BNIM) developed by Wengraf [18] in order to produce narratives relating to life events.

\section{First interview}

The first interviews were conducted either at the GAMS offices $(n=8)$ or in the women's own homes $(n=$ 7). The interviews lasted from 30 minutes up to an hour and a half, with an average of 45 minutes. An explanation of the objectives of the study was provided to the women before the beginning of the interview so they would know that FGM would be discussed. Then, at the start of the interviews, the women were all asked this one, broad question: Could you tell me about your life experiences, and in doing so, include any story in your life that you think important? The women were encouraged to talk freely about their lives and to tell as much or as little of their story as they wanted. The women's stories were recorded, and their consent was asked for beforehand. Only one woman refused to be recorded, so notes were taken.

This first interview enabled the analysis to start by constructing lifelines for each woman and if a woman specified or put an emphasis on an event during the interviews, that event was considered significant. A 'lifeline' is a visual depiction of a life story which displays events in chronological order and shows the importance of events [19]. We drew along an $\mathrm{x}$ axis with events entered in chronological order, in such a way that the main events were visually represented along with the link to any environmental context. Additional file 1 shows a fictive vignette of a typical reconstructed story from different participants after the 1st and 2nd interviews.

Thus, hypotheses of TPs were inferred from life stories in relation to existing norms embedded in the patriarchal system and associated with FGM, such as: keeping virginity, beauty and purity, ensuring the 
rite of passage to womanhood and marriageability, ethnic identity, being subordinate, and the acceptance of pain and suffering that women must endure without complaint.

\section{Second interview}

The second interview was conducted for all the 15 women in their own homes and lasted from 50 minutes to one hour and 40 minutes; an average of 50 minutes. Within this length of time, the women were able to: (i) confirm the hypotheses of TPs raised after Step 1, (ii) narrate more events and complete the lifelines, and (iii) identify further relevant turning points, if any. The second interview was guided by semi-structured questions that were unique to each woman according to their initial narratives. This enabled us to complete and validate the lifelines with every woman, with a visual representation of the significant events that led to a change of attitudes towards the practice of FGM. After the confirmation of individual's TPs, we pursued with a comparative analysis of all the transcripts, case sheets and lifelines in order to identify common categories of TPs across the range of life narratives. In doing so, we noticed that some of the TPs overlapped, so we grouped them again in accordance with those similarities. We moved back and forth, rearranging the groupings through discussion with all co-authors until we arrived at six categories of TPs. These are as follows: TPs related to encounters with health professionals; education; social interactions with other cultures and their own culture; motherhood and the urge to protect daughters; repeated pain during sexual or reproductive activity; and to the fact of witnessing harmful consequences of FGM towards loved ones.

\section{Ethical considerations}

During the recruitment and before the beginning of each interview, we informed each participant about the objectives of the study, guaranteed confidentiality and obtained informed consent for their participation. The study received approval from the Ethics Committee (Comité d'Ethique Hospitalofacultaire) of Saint Luc University Hospital.

\section{Results}

\section{Participant Characteristics}

The age of the women informants varied from 23 to 53 years old, with a median age of 39 . The age when FGM was performed varied from 5 to 14, with a median age of 7 . There was a range of women from across East (33\%) and West (66\%) Africa. They had been living in Belgium for a median duration of 6 years. The other characteristics are presented in Table 1 below. 
Table 1

Summary of participants characteristics at the time of the interview $(n=15)$

\begin{tabular}{|c|c|c|}
\hline Variables & $\mathbf{N}(\%)$ & Median/Range \\
\hline Age of the woman at time of interview & & $\begin{array}{l}39 \text { years }[23- \\
53]\end{array}$ \\
\hline Age when FGM was performed & & 7 years $[5-14]$ \\
\hline $\begin{array}{l}\text { Region of origin: } \\
\text { East Africa } \\
\text { West Africa }\end{array}$ & $\begin{array}{l}5(33 \%) \\
10(66 \%)\end{array}$ & \\
\hline $\begin{array}{l}\text { Level of education: } \\
\text { Primary school } \\
\text { Secondary school } \\
\text { University }\end{array}$ & $\begin{array}{l}1(0.6 \%) \\
7(46 \%) \\
7(46 \%)\end{array}$ & \\
\hline Length of stay in Belgium at time of interview & & 6 years $[1-15]$ \\
\hline $\begin{array}{l}\text { Method of entry to Belgium: } \\
\text { Asylum } \\
\text { Family reunion }\end{array}$ & $\begin{array}{l}13 \\
(86.66 \%) \\
2(13.33 \%)\end{array}$ & \\
\hline $\begin{array}{l}\text { Marital status at the time of the interview: } \\
\text { Married to an African man (same community) } \\
\text { Married to an African man (other community) } \\
\text { Married to a Belgian }\end{array}$ & $\begin{array}{l}6(66.66 \%) \\
1(11.11 \%) \\
2(22.22 \%)\end{array}$ & \\
\hline $\begin{array}{l}\text { Divorced once but now cohabiting with a Belgian at time of } \\
\text { interview }\end{array}$ & $6(40 \%)$ & \\
\hline Total number of children at time of interview & 25 & \\
\hline Number of children per woman & & $2[1-4]$ \\
\hline Number of children born in Belgium & $15(60 \%)$ & \\
\hline Woman giving birth to at least 1 girl & $11(44 \%)$ & \\
\hline Woman with 1 child left in the country of origin & $1(0.4 \%)$ & \\
\hline Additional file & & \\
\hline
\end{tabular}

Our results confirmed the practice of FGM as a social norm and revealed six TPs which encouraged the women participants to begin to change their attitudes towards the practice.

\section{Attitudes towards FGM as a mandated social norm}

The women in our sample confirmed that FGM is indeed a powerfully enforced norm, and they were forbidden to speak about. It was considered taboo, and they could not discuss it with their siblings. They reported that they were forbidden by their grandmothers to look down at or touch their private parts. 
However, their mothers were proud to show off to new members of the community after the procedure. Certain women reported that they themselves had asked to undergo FGM, to avoid being mocked by peers and to be able to serve men tea and food. They also believed they would be considered clean, hygienic, more beautiful and likely to keep their virginity for marriage. This was believed to preserve the family honor and morality of girls and women.

At home we did not talk about it; it was taboo. We were forbidden to tell others what had happened ... Nobody spoke about how it happened ... a girl must be excised otherwise she will not be a virgin, so she will always run after men. She cannot control herself, she will run after all the men she will meet and so we must go through that to preserve our virginity and not be unfaithful after marriage ... So, virginity has a lot of weight in that sense. (Interv_6)

The other related norms embedded in the patriarchal system were for the elders to be obeyed and the grandmothers to be the guardians of the tradition, forced marriage, how women ought to behave in the community and that women must endure pain and suffering without complaining. Most women explained that after FGM, forced marriage will follow. Gender roles were carefully reinforced, either by their mothers or their grandmothers: for instance, how a woman ought to behave in the community and be submissive to her husband, and how they should endure pain and be brave.

One woman recounted how she was given a white sheet by her father as a gift on the day she was cut while she was expecting sweets and toys as she was 6 years-old. When she asked about it, she was told that it was for her wedding. She was later forced to marry an old man whom she met only on the wedding day.

My dad chose someone I did not even know, an old man, far older than I and I was forced to marry him ... it's very difficult, (silence) because it's something that stays with you ... because you are being raped. I do not call that a marriage, it's a rape... (Interv_1)

\section{The main turning points that led to changes in the women's lives}

\section{1) TPs related to an encounter with health professionals}

These TPs concerned events where the women encountered a health professional: a gynecologist, a psychologist, a social worker, etc. For example, during gynecological visits, they women reported that they were shocked to be told that they did not have a normal vulva, and shown the intact anatomy of the vulva of their daughters, different from their own, leading them to understand the difference between an intact vulva and one that has been mutilated, as well as some negative consequences of the practice of FGM. They also mentioned that this shock led to the awareness that what they had thought was a 'normal' vulva (one that was "pure and beautiful" after FGM) was mistaken. Other women mentioned that they 
were surprised, confused and felt anxiety at the news of what an intact vulva looked like. One participant had been persuaded that all women, including white women, were like her. The picture shown by the doctor brought on an understanding of the organ that had been lost and led participants to question what it means to be a 'normal woman'. For some women in our sample, this led to taking action for a deinfibulation procedure. Others, at the time of the interview, were considering having a reconstruction of the clitoris.

So I went to see a gynecologist at a family planning clinic. She put me on the table and examined me and said you're cut and closed ... She put my daughter on the table too and showed me, you see she is not cut, she is intact not like you ... So for the first time I saw the difference between my daughter and myself (Interv_11)

When you visit a gynecologist, you are surprised when the doctor tells you that you are not 'normal'. With the expression of his face ... he looks and looks, he closes his eyebrows and says to you like this: you're not normal ... and I was confused and anxious ... And you realize, after explanation with photos, the difference between the normal and abnormal private part. So, I say, I have never seen the thing between the legs... (Interv_8)

\section{2) TPs related to education}

This type of TP involves events such as lectures on anatomy and sexuality at school and university, where some women, enrolling at medical school and attending anatomy lectures, started changing their views. Schools and universities have been eye-openers. The knowledge gained contributed to the feelings of shock and anger experienced by most women and this made them change their attitudes towards the practice. The anatomy lectures contributed to the knowledge of the consequences of FGM and what a normal anatomy of a woman ought to be.

But during my studies, I realized some things and it was a shock ... The first time I saw the genital organ of a woman, I said ah ... so I lost this part of me in the excision ... But hey, it's a bit what like I looked as well. But it must be said that this operation is very traumatic. We only perpetuate the tradition of our ancestors. All you gain is pain and sorrow. (Interv_13)

\section{3) TPs related to social interactions}

These TPs relating to social interactions are two-fold. One is in relation to interactions with other cultures and involved events where the women heard the noise of urine at refugee centers, got married or had a relationship with a European man when they came to Belgium. Migrating from their country of origin to Belgium contributed to raised awareness of difference of cultures, and a sense of not being defined exclusively by FGM. The shock provoked by the noise of urine and as the women noticed that "women are urinating like men" made them question something that they had previously thought was normal. 
They no longer viewed women as having to endure pain and suffering when men from other communities made them aware of the possibility that their sexual lives could be experienced without pain or complication during intercourse.

When you come here, you discover that not all women are like you. Because you see women go to the bathroom, and their pee makes a noise ... (laughs). So I asked myself 'What have they got there?' And I asked my doctor once, 'You're not circumcised?' She says 'No'... then I understood why their pee makes noise. (Interv_14)

The second interaction is within the women's own culture, when they were told of the reasons why FGM is performed - in order for them not to be promiscuous before marriage -and they saw the opposite happening around them in the community. This made them realize the lies and the deceit.

On the one hand I saw that it was false, that we were told lies, because I saw Fulani women who prostituted themselves, and I asked myself some questions ... these circumcised girls prostitute themselves - how does it happen? ... I also saw some circumcised girls who became pregnant before marriage and brought shame upon their families. (Itnerv_2)

\section{4) TPs related to motherhood and the urge to protect their daughters}

The women in our sample wanted the best for their children. Those of them who had girls reported that at some point or other they had been put under pressure by mothers, mothers-in-law and grandmothers or aunts, the keepers of the tradition, to put their own daughters through FGM. The pressure from other women in their families made them recall their own experiences and brought back vivid memories of the whole procedure. Some talked about pain in the womb, anger, nightmares and the urgent need to fly away to escape the danger. The prospect of perpetuating the tradition on to the next generation through their own mothers, mothers-in-law and grandmothers triggered a change in views about the practice for several women, creating a sense of apprehension as well as a duty to protect their daughters, which in turn changed their views of what it means to be a good mother. According to their previous beliefs, a good mother would put her own daughter through FGM; after becoming mothers themselves, they did not want to put their daughters through what they had experienced. They were caught in a dilemma of loving both their mothers and their daughters thus, disappointing their mothers by not wanting to destroy their daughters through FGM.

My husband could not say 'no' to his mother and it had become very serious, something had to be done to protect my daughter from the influence of my mother-in-law ... I tried to tell him we shouldn't listen to his mom for everything and he answered me, "Aren't you yourself excised? So why not your daughter? You see?" And I did not want that for my daughter... (Interv_4) 
I was destroyed by my mother and my grandmother - I can say that, since they have done something horrible to me ... I love them but when my in-laws wanted to excise my daughter, as was usual. But I opposed. (Interv_15)

\section{5) TPs related to repeated pain during sexual and reproductive activity}

The sexual and reproductive aspects identified as TPs were mainly related to repeated pain, childbirth and sexual activity: pain felt during the procedure of FGM when the participants were little girls; painful monthly periods as adolescents; pain during their first experience of sexual intercourse after their marriage; and pain during childbirth. The repeated pain during sexual intercourse ensured the women only took part in it out of duty towards their husbands, rather than for pleasure. They used to think that experiencing pain during sexual intercourse was normal until they developed an awareness of what could be a sexual activity. They then came to understand the true consequences of FGM.

But then what we do not understand is how much it hurts ... it's horrible and it follows you everywhere ... even in adulthood, in your teenage years when menstruating, when you get married, when you have sex with your husband, if you give birth, if you go through a caesarean...you see? The pain follows you everywhere and it's horrible. (Interv_9)

I had convinced myself that I would not be able to have a fulfilling sex life, and I was right because when I got married, it opened the door to another phase of a woman's life of suffering ... It gives no benefit, just suffering and I find that men also suffer, not only women. (Interv_10)

\section{6) TPs related to the fact of witnessing some harmful consequences of FGM towards loved ones}

These TPs are related to events that happened to the women's loved ones and that gave rise to stressful emotions for them. For instance, the participants in our sample reported events such as the death of a sister after the procedure, witnessing their husbands being battered by their own families for not wanting to comply with the tradition, and the death of a sister in childbirth. Such events made the women realize the harm caused by FGM.

... Because after our excision, we stayed with an old woman for 20 to 30 days, but my sister only made it for 6 days. She had a high fever and she bled a lot and the old woman she kept changing cloths and was made to drink various concoctions, until she died the following day... (Interv_12)

So, the day I had to flee the country came when we were all sitting together as a family, my family, my husband's family and my husband was tied up and beaten in front of the children because he dared to 
say 'no' to his family. I agree with my wife, I am not going to cut my daughter. Because my husband being a nurse knew the consequences too. So that's when I had to run away. (Interv_3)

\section{Discussion}

\section{Understanding the significance of TPs in the changing of attitudes towards the practice of FGM}

This paper identified and described turning points defined as significant events which created an awareness that challenged the norms embedded in the patriarchal system and associated with the practice of FGM. The TPs in the lives of the women who participated in our study occurred as a result of events where the women either encountered health professionals or attended educational settings and through that education became aware of the normal anatomy of the female genitals. Moreover, experiences of motherhood were reported when pressures from their mothers-in-law, their own mothers and grandmothers made them question what it meant to be a good mother to their own daughters. Another type of event related to TPs was found to be linked to social interactions within one's own culture or with other cultures. The events related to reproductive and sexual activity included pain during menstruation, childbirth, and repeated pain during sexual intercourse. As other authors reported about TPs related to other issues than FGM [20], the TPs found in our study created either "sudden" awareness from a single event or "gradual" awareness from repeated events.

Certain norms embedded in the patriarchal system were challenged through the TPs described in our findings and are mainly related to what it means to be a member of one's community, what it means to be a normal woman and what it means to be a good mother.

\section{Challenging what it means to be a member within the community and a normal woman}

The different TPs that led to a change of attitudes towards FGM in our study frequently challenged the norms of what it means to be a 'normal' woman in the eyes of the community, and what it means to be 'a member of the community' in a patriarchal system. The community dictates what a normal woman (according to it) is supposed to be and do. For example, a normal woman is supposed to be cut, to behave in a certain way in the community, to be a virgin before marriage, to endure pain and suffering and not to show these emotions. Also, a normal woman does not experience any sexual desire and pleasure. If a girl is cut, she is a full member of the community.

The norms related to FGM and embedded in the patriarchal system which were challenged by the women, made them to become more conscious of the gender roles their communities had bestowed on them. Challenging these related norms is somehow challenging the "invisible cage" imposed by the gender roles the patriarchal system has established [10]. They came from communities where both girls and boys are 
taught these gendered relationships to power throughout their lives. This explains why the women used to see the practice of FGM, as well as other related norms, as normal. However, the gender roles consciousness evolved through events in the women's lives where they began to question the legitimacy of what they used to consider normal. The realization of what the women considered to be simply everyday life was challenged and changed by what now constitutes for them a normal woman.

The consciousness of gender roles enabled a platform from which to acquire new knowledge through turning points, which was added to the knowledge gained during childhood. For Lawrence and Valsiner [21], new information integrated into an individual's previous understanding makes the individual to either focus on or reject the new information. The women in this study focused on the new information and came to learn for example the normal anatomy of female genitals (new information); they then processed it and internalized it into new knowledge (normal anatomy). The new knowledge in this case helps to challenge what has been internalized in childhood. However, this happened through the recognition of experiencing certain emotions such as anger, shock etc. Yet, the right to the recognition and expression of their own emotions is something that had until then been denied to these women, as they were raised in communities where they were taught as young girls that it is normal for women to endure pain and suffering without complaining.

\section{Challenging what it means to be a good mother within the community}

The TPs in our study also challenged the norm of what it means to be a 'good mother', as good mothers according to the norms in the community are expected to ensure their own daughters meet all requirements of the patriarchal system, including the practice of FGM. In this case, being a good mother meant that they did not want to put their daughters under FGM. Thus, the desire to protect their own daughters made them experience ambivalent feelings. Indeed, they wanted to hate their mothers for putting them through FGM, but at the same time they understood that they had wanted somehow the best for them. We therefore hypothesize that turning points that generated some emotions may be associated with conflicts of loyalty which the women need to come to terms with if new values and norms are to be internalized. Being a good mother is therefore connected to the existing core value of caring for children. Mackie [22] put it well in saying that the most important basic personal value of parents worldwide is to take good care of their children and protect them from harm. When, in our case, mothers were put under pressure (for example, phone-calls to put a daughter through FGM, or the decision of a mother-in-law to excise the woman's daughter), they did not necessarily change what Mackie identifies as their basic values [22]. Rather, the basic value, like 'being a good mother' is reinforced, but takes on a new meaning and a new outcome.

\section{Strengths And Limits}


There are several limits to our study: our sample of 15 women is relatively small, and some sub-groups of women may be under-represented or over-represented. For instance, none of the women in our sample were single mothers, and half of them were cohabiting with or married to a Belgian man at the time of the interview. Due to our snowball procedure, there might be a selection bias in our sample, and we cannot exclude that other turning points might have emerged from further interviews with other women. However, due to our rigorous approach of analysis and the fact that we allowed the women to co-construct our findings with us through repeated and participative interviews, we believe that our results are trustworthy and transferable enough to be shared with the scientific community.

\section{Conclusions}

The identification of TPs in this study enabled to find norms embedded in the patriarchal system which were challenged. Coming to terms with the taboo of having emotions and feelings on the one hand, and on the other hand the conflict of loyalty that inevitably arise when one questions the legitimacy of the rules and norms of one's own community, are major challenges that may be seen as common mechanisms for succeeding in changing the attitudes towards FGM of women who originated from FGMpracticing countries and communities.

These hypotheses merit further investigation as they may pave the way for future applied research into better understanding the mechanisms by which the women in the migration context might be helped to stop perpetuating the practice and become agents of change within their own communities.

\section{Abbreviations}

FGM

Female genital mutilation

TP

Turning points

\section{Declarations}

\section{Ethics approval and consent to participate}

The women were given oral information about the study prior to the interviews and the objectives of the study were given. We stated to them that their participation in the study was voluntary and because we are aware of the sensitiveness of the topic, they may withdraw from the study at any time. They were also assured that the information obtained in this research may be published in a scientific journal, but their identity will be kept strictly confidential. All data will be kept locked in the student's office and destroyed after the PhD thesis is completed. They agreed and signed the written consent form. The study received approval from the Ethics Committee (Comité d'Ethique Hospitalo-facultaire) of Saint Luc University Hospital - Brussels with reference number: 2013/21NOV/522. 


\section{Consent for publication}

Consent to publish was obtained from the women participants.

\section{Availability of data and materials}

The datasets generated and/or analyzed during the current study are not publicly available due confidentiality reasons. The women interviewed shared their personal life stories, what they have been subjected to. We cannot breach that to the public. However, they data are available from the corresponding author on reasonable request.

\section{Competing interests}

The authors declare that they have no competing interests.

\section{Funding}

Not applicable

\section{Authors' contribution}

AA, the first author contributed to the data collection, conducted the interviews. FR helped to recruit the women participants. IA contributed to the data analysis. All authors were involved in the coding process and discussed all the steps of the analysis process until we reached and agreed on the categories of turning points. The co-authors reviewed the manuscript drafted by the first author. All the authors approved the final version of the manuscript for publication.

\section{Acknowledgement}

We would like to thank the women who participated in the study and accepted to be interviewed.

\section{References}

1. World Health Organization. Eliminating female genital mutilation: An Interagency Statement: OHCHR, UNAIDS, UNPD, UNECA, UNFPA, UNHCHR, UNHCR, UNICEF, UNIFEM, WHO.2008. http://www.who.int/reproductivehealth/publications/fgm. Accessed 15 Jan 2015.

2. UNICEF. Female Genital Mutilation/Cutting: A global concern. 2016. http://data.unicef.org/topic/child-protection/female-genital-mutilation-and-cutting. Accessed $10 \mathrm{Apr}$ 2017.

3. Leye E, Sabbe A. Responding to female genital mutilation in Europe: striking the right balance between prosecution and prevention. Gent; 2009.

4. Alavi R. Female genital mutilation: a capability approach. Auslegung. 2003;26(2):1-25. 
5. Vloeberghs E, Van der Kwaak A, Knipscheer J, Van den Muijsenbergh M. Coping and chronic psychosocial consequences of female genital mutilation in the Netherlands. Ethnicity and Health. 2012;17:677-95.

6. Whitehorn J, Ayonride O, Maingay S. Female Genital Mutilations: Cultural and Psychological Implications. Sexual and Relationships Therapy. 2002;17(2):161-70.

7. Cook RJ. Ethical concern in female genital cutting. African Journal of Reproductive Health. 2008;12(1):7-16.

8. Ahmed HM, Shabu SA, Shabila NP. A qualitative assessment of women's perspectives and experience of female genital mutilation in Iraqi Kurdistan Region. BMC Women's Health. 2019;19:1-12.

9. Farage MA, Miller KW, Tseghai GE, Azuka CE, Sobel JD, Ledger WJ. Female genital cutting: confronting cultural challenges and health complications across the lifespan. Women's Health 2015;11(1):70-94.

10. Monagan SL. Patriarchy: perpetuating the practice of female genital mutilation. Journal of Alternative Perspectives in Social Sciences. 2010;2(1):160-81.

11. Heise L, Manji K. Social norms. UK: University of Birmingham; 2016.

12. Carlsson $\mathrm{C}$. Using turning points to understand processes of change offending: notes from a Swedish study on life courses and crime. British Journal of Criminology. 2012;52:1-16.

13. Wheaton B, Gotlib, IH. Trajectories and turning points over the life course: concepts of themes. In: Gotlib I H WB, editor. Stress and adversity over the life course: trajectories and turning points. Cambridge: Cambridge University Press; 1997.

14. Enz KF, Talarico JM. Forks in the road: memories of turning points and transitions. Applied Cognitive Psychology. 2015;

15. Hareven TK, Masaoka K. Turning points and transitions: Perceptions of the life course. Journal of Family History.1988;13:271-289.

16. Reimer D. Subjective and objective dimensions of turning points. Social Work and Society International Online Journal. 2014;12(1):1-10.

17. Clausen JA. Gender, contexts and turning points in adult's lives. In: Moen P, Elder Jr GH, Luscher K, editors. Examining lives in context: perspectives on the ecology of human development. Washington, DC: APA; 1995.

18. Wengraf T. Short guide to biographical narrative interviewing and analysis by the SQUIN-BNIM method. London: Middlesex and East London Universities; 2008.

19. Adriansen HK. Time line interviews: a tool for conducting life history research. Qualitative Studies. 2012;3(1):40-55.

20. King G, Cathers T, Brown E, Specht JA, Willoughby C, Polgar JM, et al. Turning points and protective processes in the lives of people with chronic disabilities. Qualitative Health Research. 2003;13(2):184-206. 
21. Lawrence JA, Valsiner J. Making personal sense: an account of basic internalisation and externalisation processes. Theory and Psychology. 2003;13(6):723-52.

22. Mackie G. Ending footbinding and infibulation: a convention account. American Sociological Review. 1996;61(6):999-1017.

\section{Additional Files}

Additional file 1: A fictive vignette of a typical reconstructed story from different participants after the 1st and 2nd interviews.

Additional file 2: COREQ checklist 